\title{
SWT: Designing Performance Wear for Balanced Beachwear Practice
}

\author{
Vanessa da Graça Mendes, Mário Say Ming Kong, and Regina Aparecida Sanches
}

\begin{abstract}
In order to create a type of body art that relies on sun tanning, it's essential to create a debate on what is a balanced UV exposure. While there are problems between lack of and excessive sun bathing, other threats to the well-being of the individual lay with the beaches' biosphere, which may endanger the user as well. Acknowledging these circumstances is a necessary step in the process of making the perfect body suit for this kind of practice. As part of a good design process, it takes on the many challenges the intensive beach practitioner faces and incorporates them in the manufacturing process, looking for the required adaptions according to multiple factors.
\end{abstract}

Index Terms-Body art, colour behaviour, photochromic colorants, user centred design.

\section{INTRODUCTION}

Beachwear relies on a practice that is conditioned to sun exposure. The debate between health and sun bathing is still ongoing, due to the scientific findings up to date. Regarding matters of design, technology and colour with the purpose of improving today's beachwear, there is the possibility of providing higher safety standards from elements of the local biosphere, which may present hazards to human physical integrity. Harmony and balance in the practice of surfing could be improved by tackling important aspects, many times overlooked, forcing fashion design to consider a broader spectrum of factors that contribute to physical safety, health and performance, focusing mainly on the user's needs.

\section{SUN EXPOSURE VERSUS SUN PROTECTION}

\section{A. Sun Restriction}

There is an undeniable relationship between sun exposure and skin cancer.

Non-melanoma skin cancers are the most common malignancy of this type worldwide. Despite the rising of this global healthcare problem, NMSC's are relatively non-lethal and curable, even if the 3 main types of skin cancer (basal cell carcinomas (BCC), squamous cell carcinomas (SCC) and, more rarely, malignant melanoma $(\mathrm{MM})$ ) are mainly caused

Manuscript received May 23, 2019; revised July 11, 2019.

V. G. Mendes and M. S. M. Kong are with Lisbon School of Architecture, University of Lisbon, Rua de Sá Nogueira, Pólo Universitário, Alto da Ajuda 1349-055 Lisboa, Portugal (e-mail: vanessa.7g7mendes@gmail.com, mskong@fa.ulisboa.pt).

R. A. Sanches is with Universidade de São Paulo, Avenida Arlindo Bettio, 1000 - São Paulo, Brasil (e-mail: regina.sanches@ups.br). by UVA and UVB from solar UVR, still, the majority of skin cancers cases are non-lethal. Questions arise about this issue, regarding the lack of knowledge and correlation surrounding the amount of sun exposure required to cause skin cancer [1] [2], as well as other factors that contribute to the increase of this incident.

Ozone depletion, air pollution, pollutant arsenic and climate change have been reported to be associated with MM, SCC and BCC but, studies fail to individualize all the environmental risk factors for skin cancer [3], and there also might be other factors involved in causing this issue that are still unknown or left out of the equation. These factors could possibly reveal the full extension of the present problem.

\section{B. Sun Exposure}

Having referenced the relationship between UV radiation and skin cancer, a more in-depth analysis about tanning's pros and cons is crucial to reach full understanding about the basis of the human evolutional adaptation and the need for sun bathing.

Human skin colour is mostly defined by sun exposure and the need for vitamin D synthetization. The primordial human skin is dark and rich in melanin due to the need for protection against UV radiation. As human species migrated to other regions of the globe with less sun exposure/intensity, bodies have evolved to be able to capture enough sun light, so that enough vitamin $\mathrm{D}$ could be produced to satisfy their physiological needs [4].

When controversy about skin cancer arose due to increasing incidents, prevention campaigns came up with a zero-tolerance policy regarding sunbathing as their main strategy, in an attempt to solve the problem [2]. The recommendations issued for this type of intervention fail to provide a broader view in regard to the need for sun bathing in moderation, due to our own body's nature, considering only one side of the spectrum of information about this subject's present knowledge.

\section{Consequences that Require Balance}

Until this day there still seems to be a lack of understanding on how much sun exposure is needed to cause skin cancer [1], and how much vitamin D is required to satisfy humans physiological needs [2]. Despite the present paradox concerning sun exposure and protection, some guidelines are universally used as a mechanism for safer sun bathing.

A more comprehensive approach in information dissemination about safe sun exposure has been adopted, with a more balanced overview, pointing out the importance of sun bathing, although still failing to enter in detail about the true reasons behind the need for this balanced practice [5]. 
To tackle the root source of this problem, there is a need for a focused analysis about the consequences caused by both polarities of practice. As seen in Table I, neither of these extremes are beneficial for general health but, when compared side by side, sun deprivation reveals to cause far more damage to human health than sun exposure in both quantitative and qualitative maters.

TABLE I: RESUMED CONSEQUENCES COMPARISON

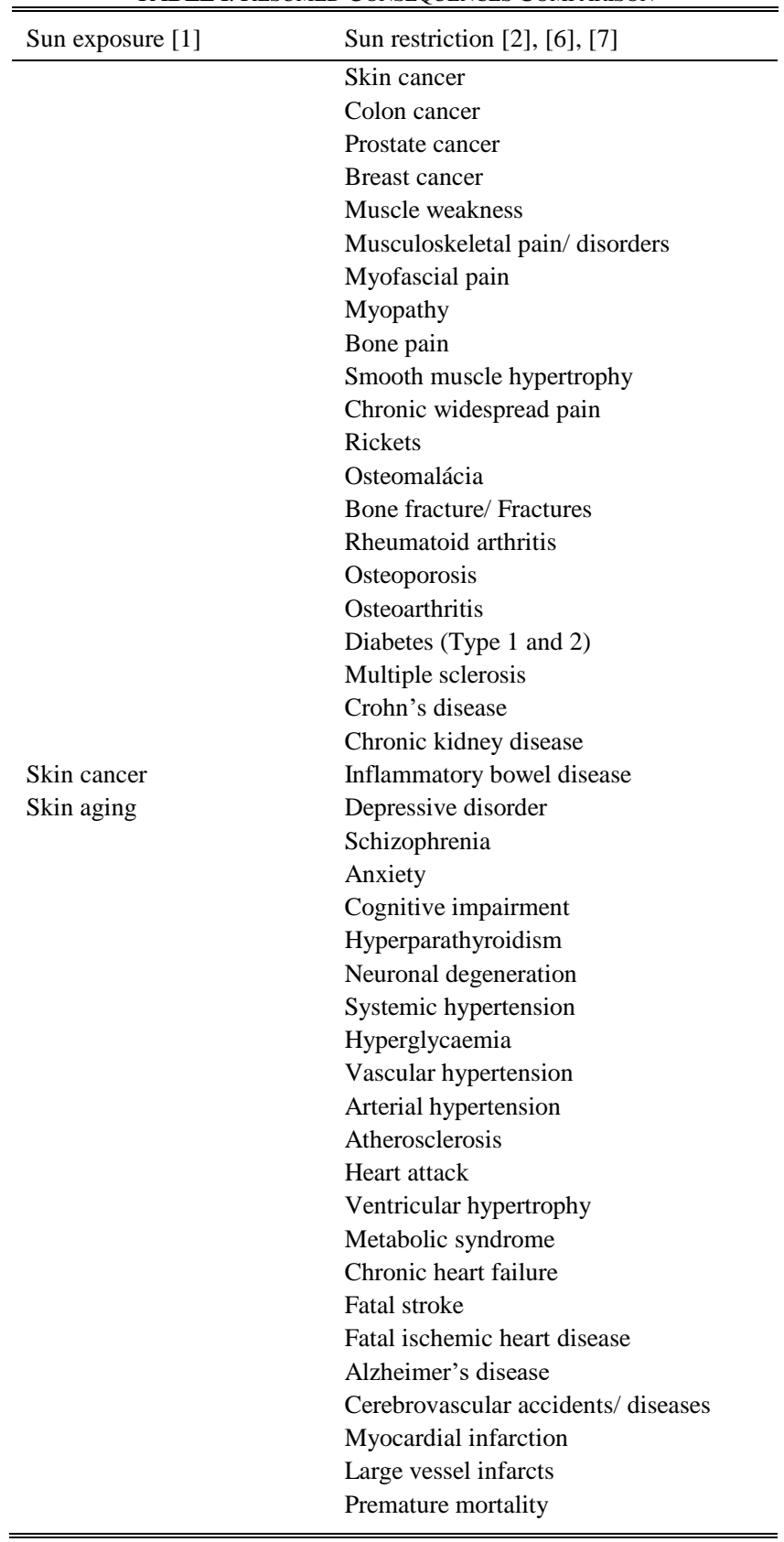

\section{BALANCED PRACTICE}

The issue concerning how much exposure is too much is a very delicate matter and a hard one to concretely define and achieve. A balanced beach practice is a complex definition that depends mainly on time of exposure, latitude, sun intensity and skin type [6].

Despite the difficulty to define concrete balanced beach practices, main guidelines such as avoiding main heat hours and sun burn are moderately efficient universal tips that should be followed [5].
Considering factors associated to body and skin health a broader spectrum is needed, analysing other hazards such as the local biosphere.

Through colour, there might be the potential to create a system that allows safe tanning by signalling time of practice through colour, plus, enabling un-motivational signals to continue solar exposition through the triggering of colours that do not motivate extensive UV exposure, due to the emerging of unfavourable tones according to the involving biosphere.

\section{Surroundings AwARENESS}

The basic function of the proposed beachwear is to create a solar tattoo. Yet, in order to bring to life a suit that is safe for the user in a surfing environment, certain precautions need to be taken into consideration.

Observing the water's biosphere, there is a common history concerning dangers involving water and its surroundings: Predation.

Predation in water, in general, correlates to colour. As an example, the Lake Victoria cichlid fish whose colour polymorphism is in orange blotched tones, suffer with higher predation frequency, in contrast to its less contrasting counterparts [8].

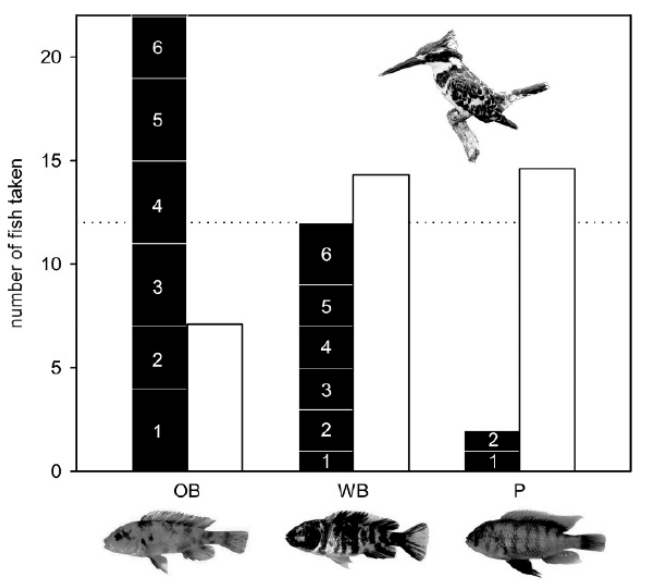

Fig. 1. Predation frequencies for the different cichlid fish colour polymorphism: Orange-blotched (OB), white blotched (WB), and plain (P) N. omnicaeruleus in the experiment.

For each morph, black bars represent the total number of fishes taken in each of the six trials; trail numbers are indicated. Open bars indicate the expected numbers of fish taken, adjusted for the changing morph proportions after each predation event. The dashed line should indicate an 'even' distribution [8].

In aquatic species, there is a reason for the predation frequency, correlated to "fire" and bright colours.

It is possible to observe in Fig. 1, that gammarus plurex, fire colours correlate to weakness, sickness and more vulnerability to predation. A study shows results that prove not only that fire colours are the biological colours that represent inflammation/ infection/ bleeding but, despite the variables of these natural colours, if artificial colour is used to mimic sickness in healthy specimens, it will attract more predators than the sick fishes that are the actual easy prey. 
Through this behaviour it is possible to conclude that strong colours, attract more predators for being more vibrant, in other words, fiery statement colours create easier targets [9].

In the beach environment, specifically, the species that lurk to attack the beachwear user, belong to a diverse local biosphere that appears to target prey under the same exact circumstances.

Despite the notion of the aggressiveness of sharks, other species attacks rank higher in fatalities. Bees, wasps and snakes are just a few examples to reference other potential dangers that can be found on the beach environment.

Concerning shark threats, human attacks incidence increased with the wetsuits technological evolution that allowed higher time spent in the water, increasing the time of exposure between humans and sharks.

As a concern regarding good design practices, it is highly important to underline the fact that, in order to conceive a good beachwear oriented to this user, the same mistakes from the past must not be repeated; such as the international lifeguard suits, which colour of choice is the one sharks are most attracted to: international orange [10].

Summing up, fire colours (more specifically, international orange), are colours that for the many reasons referenced above, should be avoided as prominent in the designing of the desired beachwear.

\section{TECHNOLOGICAL FUNCTION}

\section{A. Basic Need for Colour and Biosphere Mimicry}

Despite the disadvantages of fire colour in the conception of the suit's design, there might also be an advantage in its use.

Colour in the biosphere can serve three main purposes: thermoregulation, intraspecific communication, and evasion of predators.

General colours and tones of animals resemble the backgrounds of their habitats, as seen by predators. Therefore, the colour sample should assume a compromise between cryptic and conspicuous patterns that can match a specific environment accordingly [11].

Mimicry of nature characteristics in sportswear technology, is a way to improve human performance in many ways. One great example is the Fastskin swimsuit, mimicking and modelling it after the shark's skin, making it possible for athletes to brake records consecutively in a very short period of time, thanks to this competitive technology.

Controversy arose the moment that Fastskin became available to the user. FINA's opened a debate upon regulations and what could be considered right to adopt in terms of fair play, evaluating moral and ethical standards in the process of determining what could be used and what could be classified as a performance enhancer. Consequently, the suits were temporarily banned in the absence of consensus.

Despite the issues surrounding it, it's undeniable that the Fastskin suit is a masterpiece of efficiency; basing itself on animal biology was key to take sports to the forefront of new technologies [12].

Searching for new ways to increase performance, based on a state-of-the-art knowledge regarding biology, dermatology and using it towards technological advancement is required to obtain the desired function.

\section{B. Solution through Photochromic and Thermochromic Colorants}

Carrying the responsibility of a practice that relies on sun exposure in an environment with several biological threats to the human physical integrity, photochromic/thermochromic fashion materials might be the answer that could combine a need for camouflage during practice time and the need for balanced sun bathing, necessary to maintain health.

The colorants intended to be applied, belong to the category of smart textiles that, by definition, imply a three-class division: microencapsulated, electronic and nanotechnology. These fabrics are intended to be used with the purpose of contributing for the health and communication against the adverse effects of and excessive exposure to Ultra violet radiation.

These commodity textiles could be made following two types of production: Premium textiles and emerging technologies, both of which could be differentiated by their design and materials applied. With visual effects perceived almost as science fiction, they could be obtained through the use of smart fibbers; other way is through a posterior application of certain compounds in which could be observed similar effects to the ones obtained through the use of smart fibbers but, could not be obtained through the use of smart fibbers alone.

A smart fibber is a fibber type that can react to a stimulus like light, heat, sweat, wound, among others; and, where the stimuli occur, it reacts accordingly and, where there is no stimuli, the fibber remains the same [13].

A photochromic colourant is defined by its reaction of colour change when exposed to UV light. This phenomenon called photochromism, was discovered in the XIX century but, only begun to rise in popularity within the scientific community by the end of the XX century [14]

Photochromic textiles could be obtained through the application of microcapsules that contain photosensitive colourants, which allows photochemical reactions with efficiency when found in its liquid phase inside the capsule.

Photochromic colourants could be divided in two categories: Organic and inorganic, in which, the first form could be preferable for many reasons, including comfort and health of both user and environment [13].

These colorants have the capacity of creating responsive and adaptive products. Chromic as suffix means reversible change in colour, and by extent, a reversible change of other physical properties as well. For the materials to change colour and shape there are different types of stimuli possible, through light (photochromic), heat (Thermochromic), electricity (electrochromic), pressure (piezochromic), liquid (solvatechromic) and/ or an electron beam (carsolchromic) [15].

Focusing on photochromics because of the intention to warn against excessive sun exposure, the main commercialized colourants of this T-Type are the spiropyrans, the spirooxazines and the naphthopyrans (also known as chromenes) [15].

In photochromic systems, due to UV radiation incidence 
upon material, concentrated heat causes molecular rearrangement trough the opening of a light ring that results in colour change, as exemplified below in Fig. 2 [15].
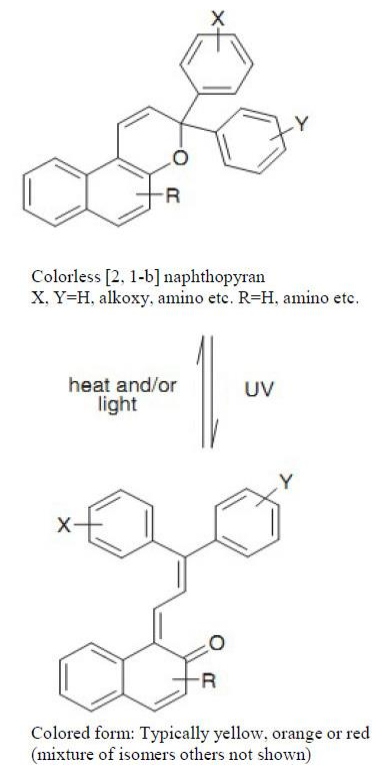

Colored form: Typically yellow, orange or
(mixture of isomers others not shown)

Fig. 2. Example of light ring opening (naphthopyrans) [15]

The goal by using photochromics or thermochromics is the incorporation of this solution in a small patch of the suit, which unifies a group of technologies combined to create the solar tattoo.

Firstly, for proper camouflage, it's intended that this area should be covered with patches that resemble the beach background tones, as a way to provide protection to the user from possible attacks of the surrounding biosphere.

Secondly, since excessive sun exposure is not desirable for health reasons, the same patches surrounding the tattoo area that has a camouflage patch shall change to colours that aren't favourable for self-protection, specifically fire tones; aiming to discourage the user to continue its beach practice.

\section{The Human Subconscious and Colour}

Colour is an important factor in man-made objects and spaces. For instance, market studies are made considering human attraction to colour and the physiological reactions, in order to better promote services and products [16]; so, any design choices should consider deeply our natural reaction and attraction to colour.

Attraction to the colour red is a part of human nature. At a physiological level, fire tones in the skin (yellow and red) are associated with a better choice of a mate [17]; to men, red is a natural indicative of sexual interest by a female, due to shifts in oestradiol levels and other hormone production, that results in flushing. Woman can occasionally, by intuition, accentuate the redness in their bodies during the fertile season by choosing to wear red clothes [18], due to red colour being widely considered as the colour of attraction.

\section{Colour Compensation through Shape}

Since the use of the most attractive colours to humans is not an option (due to biosphere circumstances), it is worth while exploring attractiveness through shape and form, as a way to provide balance to this present restriction.

As a natural characteristic of attractiveness, looking back to men's origins and primordial forms of art, up to our present days, there has been a recurring theme regarding a type of form: Curves.

Based in reconstructions from the past, Palaeolithic depictions of women, commonly referred to as "Venus" in literature, are related to voluptuous sculptures, emotionally charged by primary and secondary sexual characteristics that are prominently represented: vulvae, breasts, stomach and buttocks [19].

Physical fitness is a sign of attractiveness, as well as facial symmetry. Both features considered are indicators of good genetic design and, therefore, increase the chances for successful long-term committed partnerships [20]. This is also something which is ingrained in our subconscious, since, for early man, having access to food in a time of overall shortage, meant prosperity and health, as well as having large hips, in a time with limited health care and a high rate of infant and pregnancy mortality, meant a larger probability of survival and conceiving future generations.

Specially women, throughout time, have been valued as erotic capital, more so than men. This recent theory about erotic capital can be summed up and described in six topics: Beauty, sexual attractiveness, social grace, liveness, style and sexuality; where fitness and body curves play a large role in most of these topics, if not all of them [21].

In a direct reflection to traditional tattoo choices for women, the feminine public tend to choose floral patterns and curvy drawings that accentuate their natural body curves and, curiously, intensify the value of their physical attributes [22].

Therefore, it is wise to portend to these natural human tendencies, preferring curves that flow through the natural body forms, to accentuate the user's attractiveness and physical attributes. Therefore, the tattooing area designed in the swimming suit should abide by these rules, to balance the suits attractiveness through form and, consequently, compensating the lack of attractive attributes through colour.

\section{USER NEEDS}

Besides the already mentioned user needs concerning sun exposure and protection, against surrounding environment, other requirements must also be addressed.

Placing the user as the focal point of the design process is the major factor that enables the creation of products in a successful manner, with full acceptance by the user.

These methods when applied create more effective, efficient and safer products, and, as already mention, these goals are being considered as part of the present designing process.

In such a complex suit, it is important to find terms in order to simplify the possible benefits, making it easier for the user to understand and retrieve information in a simple manner. On average, the user is able to remember five things at a time [23], so the suit should be described in a summation of 5 simplified topics, that correspond to its main functions:

1) Ephemeral tattoo

2) Performance

3) Camouflage

4) Active consciousness

5) Well being 
Elaborating on topics, ephemeral tattoo, which is the primary function, allows the creation of the solar tattoo through UV exposure, which is a natural way of providing a tattoo without the social and health consequences that a normal tattoo can have.

Secondarily, the performance function, is a transversal characteristic to any suit prepared for beachwear and sports purposes, such as the surfer suit, which is the main case study.

Third topic, the camouflage characteristics, they aim to prevent any attacks from the surrounding biosphere.

Fourth topic, active consciousness, is referring specifically to the photochromic/thermochromic technology, directed to warn the user against excessive UV exposure, changing colour to one that doesn't promote a continued practice, beyond the point of endangering its user.

Fifth, well-being topic is about the common sense surrounding the conception of any retail design, which is body comfort in terms of touching and feeling the fabric, as well as good fitting which is provided by good pattern making and cutting.

Another factor that allows the user to adhere to the product and its practice, is to find himself in control over a task [23], that way, it is wise to query the user through SAM (Self Assesment Manequin), in order to measure its feelings in terms of pleasure, arousal and dominance [24], and understand if the object created is accepted or not by the user consequently.

The desired objective is that the user describes the object through query as pleasant and feels dominant with it, or, in project faze, at least, demonstrates an expectancy of feeling like that as well.

Since the first step of the design cycle is the phase were the background interviews and queries take place [23], it is desired to establish contact with the user with abstract purposes to deepen the research towards its needs and satisfaction.

\section{PRESENT PROPOSALS}

Concerning the present research and the factors listed above, various components were drawn together in order to create proposals aiming to be manufactured and tested with the user.

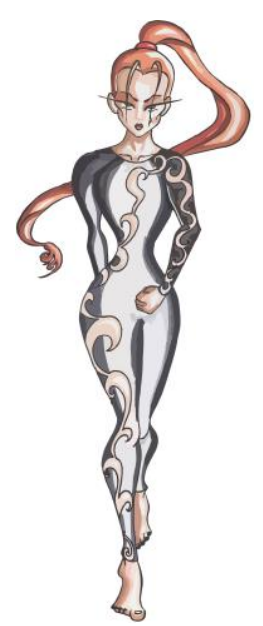

Fig. 3. First author's swimsuit illustration look before sun exposure, in its camouflage form.
Sun exposure factors, resorting to technological attributes that interfere with colour, consider user needs in terms of its natural responses to both colour and shape. Combined to bring to life an ephemeral tattooing process, that comes naturally with a healthy sports practice. All these factors take into consideration the need for protection of the user, from the possible biological hazards coming from the surrounding environment.

As illustrated below in Fig. 3, colour as camouflage of the general suit protects against the surrounding biosphere Thermochromic or photochromic colour change response, seen in Fig. 4 is, therefore, a way to warn against excessive UV exposure.

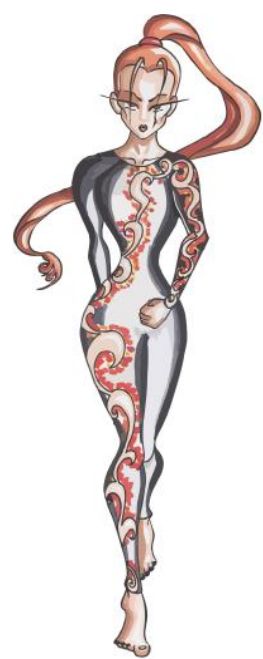

Fig. 4. First author's swimsuit illustration look after sun exposure, showing photochromic/thermochromic change.

\section{FUTURE EXPERIMENTS}

The need to query the user in terms of taste is crucial, in order to conceive the final suit's design. Technological advancement is the most important factor for the suit to work.

To conceive a solar tattoo with textile technology and other fashion materials, a clear understanding about their UV transmission properties is needed.

The main characteristics that influence UV transmission in fashion material are the following 3 [25]:

1) Reflexion

2) Absorption

3) Transmission

Different textiles have different UV protection factors that can be measured by their UV transmission, to other supports [26]. So, the creation of a solar tattoo is the combination of fashion materials that allow for both UV transmission and restrict it respectively, creating an area where melanin is stimulated and the other area, restricted consequently. In the case of a surfer suit, the larger area is the one that restricts melanin stimuli.

The final goal aims to bring together both, solar tattoo materials and the photochromic/ thermochromic characteristics that together, cooperate in the creation of a suit that allows the production of a solar tattoo on the user's skin, informing, through colour, about the safe time limit of a healthy sun exposure. 


\section{CONCLUSIONS}

The present ongoing research aims to create the ephemeral solar tattoo that comes with all the benefits of a balanced solar bathing.

Further research is needed in order to create the desired body suit that changes colour within the right molecular reaction timing, making possible to warn user about solar exposition limits, all according to user needs and taste.

\section{ACKNOWLEDGMENTS}

Special acknowledgments to Ricardo Silva from FCUL (Faculty of Sciences, University of Lisbon) for his research bibliography contributions for this paper, as well as the relevant professional contacts provided for future development of the ongoing research, regarding the content concerning biology.

\section{REFERENCES}

[1] D. Didona, G. Paolino, and U. Bottoni, "Non melanoma skin cancer pathogenesis overview," MDPI Biomedicines, Jan. 2018.

[2] J. Reichrath and B. Nurnberg, "Understanding positive and negative effects of solar UV-radiation: A challenge and fascinating perspective," The Norweigian Academy of Science and Letters, pp. 76-94. 2008

[3] G. Fabbrocini, M. Triassi, M. C. Mauriello, G. Torre, M. C. Annunziata, V. D. Vita, F. Pastore, V. D'Arco, and G. Monfrecola, "Epidemiology of skin cancer: Role of some environmental factors," Cancers, pp. 1980-1989, Nov. 2010.

[4] A. H. Steindal and J. Moan, "The evolution of different skin colours," Espen Bjertness, The Norwegian Academy of Science and Letters, pp. 114-122, 2008.

[5] Ministry of health and Cancer society in New Zealand, "Consesus statement on vitamin D and sun exposure in New Zealand," Ministry of Health, Mar. 2012.

[6] S. Sarkar, "Vitamin D for depression with a seasonal pattern: an effective treatment strategy," International Physical Medicine \& Reabilitation Journal, pp. 91-99, 2017.

[7] P. Nepps, "Vitamin D and mood disorders" The Journal of Lancaster General Hospital, vol 1, no. 3, pp. 114-115, 2006.

[8] M. E. Maan, B. Eshuis, and M. P. Haesler, "Color polymorphism and predation in a Lake Victoria cichlid fish," Copeia, no. 3, pp. 621-629, Sep. 2008.

[9] T. C. M. Bakker, D. Mazzi, and S. Zala, "Parasite-induced changes in behaviour and color make Gammarus Plurex more prone to fish predation," Ecology, vol. 5, pp. 1098-1104, July 1997.

[10] D. G. E. Caldicott, R. Mahajani, and M. Kuhn, "The anatomy of a shark attack: A case report and review of the literature," Injury, vol. 32, pp. 445-453, Jan. 2001.

[11] J. Endeler, "A predators view of animal color patterns," Evolutionary Biology, vol. 11, pp. 319-364, Dec. 2002.

[12] J. K. Craig, "The Fastkin revolution: From human fish to swimming androids," Culture Unbond, vol. 3, pp. 71-82, Dec. 2011.

[13] J. C. Sánchez, "Têxteis inteligentes," Química Têxtil, vol. 82, pp. 58-77, Mar. 2008.
[14] J. A. M. Machado, "Efeitos inovadores em tecidos para vestuário e acessórios de Moda obtidos através de acabamentos especiais," Faculdade da Beira Interior, Covilhã, Jun. 2015.

[15] M. A. Chowdhury, M. Joshi, and B. S. Butola, "Photocromic and thermochromic colorants in textile aplications," Journal of Engineered Fibers and Fabrics, vol. 9, issue 1, pp. 107-123, 2014.

[16] S. Singh, "Impact of color on marketing," Management Decision, vol. 44, no. 6, pp. 783-789, 2006

[17] Y. Z. Foo, G. Rhodes, and L. W. Simmons, "The carotenoid beta-carotene enhances facial color, attractiveness and perceived health, but not actual health, in humans," Behavioural Ecology, vol. 28, issue 2, pp. 570-578, Feb. 2017.

[18] A. B. Eisenvruch, Z. L. Simmons, and J. R. Roney, "Lady in Red: Hormonal predictions of women's clothing choices," Psychological Science, pp. 1-7, Jul. 2015.

[19] O. Soffer, J. M. Adovasio, and D. C. Hyland, "The 'Venus' figurines," Current Anthropology, vol. 4, pp. 511-537, Aug. 2000.

[20] V. O. Damasceno, J. R. P. Lima, J. M. Vianna, V. R. A. Vianna, and J. S. Novaes, "Ideal physical type and body image satisfaction of regular walkers," Sociedade Brasileira de Medicina do Esporte, vol. 11, no. 3, pp. 174-179, May/Jun. 2005.

[21] C. Hakim, "Erotic capital," European Sociological Review, vol. 26, no. 5, pp. 499-518, 2010.

[22] C. Saccaggi, "Imaging the body: A discourse analysis of the writings of people with tattoos," MA. dissertation, Dept. Psy., Pretoria Univ., 2007.

[23] C. Abras, D. Maloney-Krichmar, and J. Preece, "User-centered design," Encyclopedia of Human-Computer Interaction, Thousand Oaks: Sage publications, 2004.

[24] M. M. Bradley and P. J. Lang, "Measuring emotion: The self-assessment manikin and the semantic differential," C Journal of Behaviour Therapy and Experimental Psychiatry, vol. 25, no. 1, pp. 49-59, 1994.

[25] H. Yang, S. Zhu, and N. Pan, "Studying the mechanisms of Titanium dioxide as ultraviolet-blocking additive for films and fabrics by an improved scheme," Journal of Applied Polymer Science, vol. 92, pp. 3201-3210, Nov. 2003.

[26] Z. Bilimis, "Measuring the UV protection factor (UPF) of fabrics and clothing," Agilent Technologies: Australia, 2011.

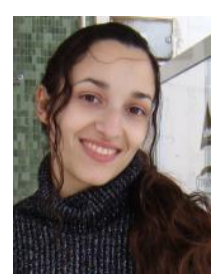

V. Mendes was born in Lisbon, Portugal, on December 29, 1988. She graduated with both diploma and master's degree in fashion design, from Advanced Studies in Design, acquired as part of a PhD study in design at the Lisbon's School of Architecture in Portugal. She aims to her research to the fashion design field, more specifically to beachwear, lingerie, leisurewear and fashion accessories.

She was a federated athlete in both sport Lisboa and benfica and belenenses athletics sections, being for several times Lisbon's regional cross champion, and, at a national level, $3^{\text {rd }}$ place in the 1500 and 800 meters. At present, she is a fashion creator of the exclusive accessory collection and responsible for clients customized orders within the Lanidor company group.

As a $\mathrm{PhD}$ candidate, Mrs Mendes has participated in 3 conferences (IEEA 2016; ICMEP 2016; ICMSNT 2017), as well as 2 other conferences (PHI 2016; PHI 2017) as part of the organization support. 